\title{
Paul Hiebert's Worldview Model: Understanding \\ Cultural Encounters
}

\&anju Sharma

\section{Abstract}

According to Paul Hiebert, worldview is a set of our assumptions which lies in the core of a culture. Worldviews provide us cognitive foundation, validate our norms, and give emotional security. His worldview model has three dimensions: cognitive, affirmative and evaluative. Cognitive dimension relates to the knowledge which guides us to perceive the reality of self and surroundings. Affirmative dimension relates to our feelings, emotions, and behavior. So we react to the action on the basis of our feelings. Likewise evaluative dimension relates to the judgment-what is right and wrong. This paper discusses how his worldview model can be used to understand encounters among the cultures. Further, it explores how culture affects the construct of social reality and vice versa. It also investigates how it is useful to theorize concepts of 'us' and 'them'.

Keywords: Cultural Pattern, Worldview, Cognitive, Affirmative, Evaluative, Social Reality

\section{Introduction}

The concept of worldview emerged during the past two decades as an important concept of philosophy, history, anthropology and Christianity. Depending on the theme of subjects, it has many definitions and no single definition has been agreed upon by all. From the philosophical perspective, it is just a general view of the world. Therefore, every individual has his/her own worldview and so does in every 'ism'. From the historical perspective it concerns with how the cultural patterns develop over time. How those patterns transform and diffuse around the world and why some cultures remain lively and some die out. From the anthropological perspective it tries to explore the theories behind the core of a culture and its configuration.

In general, worldview can be taken as a set of assumptions about the human realities. It can also be understood as a network of presuppositions through which one can understand, evaluate, and judge a reality. It is a 
lens through which one can see the world. Our worldview is formed by our education we get, the surroundings we grow in, the culture we live in, the literature we read, the philosophy we are influenced by, media and movies we absorb, and so on.

The worldview is the latest concept in anthropology which is supposed to be its youngest sibling in connection to culture. The concept of worldview through which the reality of existing world can be analyzed and discussed is very concretely described by an anthropologist Paul G. Hiebert (19322007). This paper discusses how Hiebert's worldview model can be used to understand cultural encounters. Besides, it investigates how it is useful to theorize concepts of 'us' and 'them' or 'other'.

\section{Paul G. Hiebert's Worldview Model}

Paul G. Hiebert's model gives inside understanding on dimensions of worldview and its functions. The level of culture, described by Hiebert, gives inner understanding of worldview within a culture. Here, his model is connected to analyze immigrants' integration process in the different cultural settings and to theorize the concepts of 'us' and 'them'.

According to Paul Hiebert, worldview is a totality of basic assumptions about reality which lies behind the beliefs and behavior of a culture. Those assumptions are generally unexamined and therefore highly implicit. They are reinforced by the deepest of feelings therefore, anyone who challenges them becomes a subject of fiery attack. People believe that the world is exactly the same what they see it. Supporting Hiebert's view Kraft (1979) says "the worldview lies at the very heart of culture, touching, interacting with, and strongly influencing every other aspect of the culture" (p. 53).

Worldview lies at the very inner part of a culture. Human behavior, norms, values, understanding, evaluation patterns are guided by their worldviews. It helps us to understand cultural stability and resistance of change. It guides human behavior. In general, culture is an ascribed system of beliefs, values, norms, and behaviors. Hiebert (1985) defines culture and its essential and functional functions as "the more or less integrated systems of ideas, feelings, and values and their associated patterns of behavior and products shared by a group of people who organize and regulate what they think, feel and do" (p. 30). Thus, culture defines the reality of the world. Human 'behavior and products' are the manifestations of culture that we can see, hear, experience through other senses. 
Hiebert (1985) defines worldviews as "basic assumptions about reality which lie behind the beliefs and behavior of a culture" (p. 45). Those basic assumptions are grouped in three dimensions of a culture: the cognitive, affective, and evaluative (Figure 2). There are many institutions in a society, for example, politics, technology, law, state, economy, marriage, kinship, religion, social organization, aesthetics, rites, rituals, folklore, stories, and so on. Every social institution is influenced by the above three dimensions/assumptions of a culture. Some institutions can be more influential than the others. In some factors cognitive assumptions exist in dominant role while in other affective and evaluative assumptions do.

\section{A Model of World View}

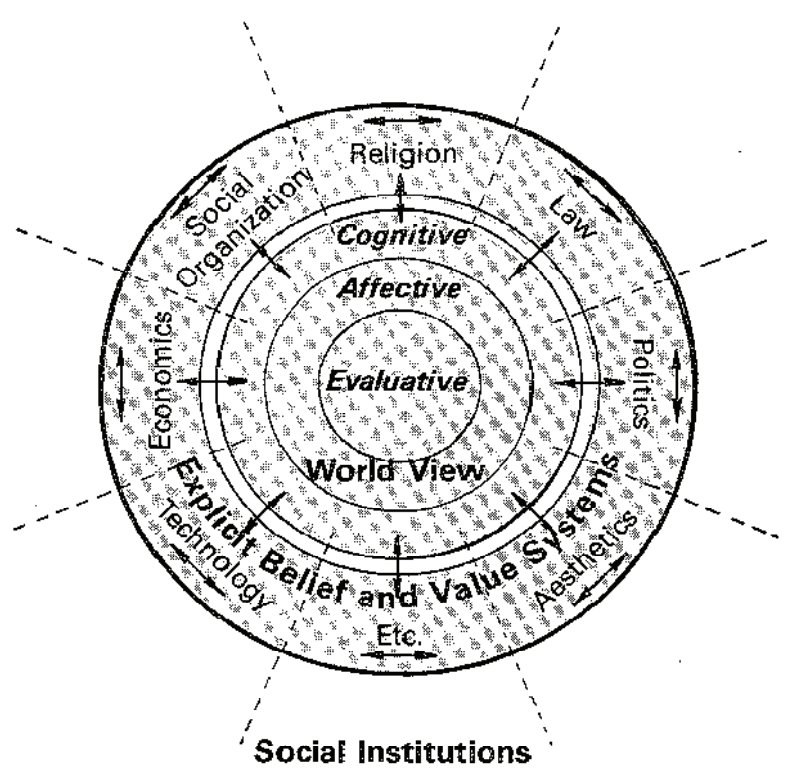

Figure 2: A model of Worldview and its three dimensions: cognitive, affective and evaluative (Hiebert 1985, 46)

\section{Dimensions of the Worldview Model}

\section{The Cognitive Dimension}

Cognitive aspect of culture relates to the knowledge which is shared by members of a community, group, and society. Without shared knowledge, community life and institutions are not possible. Knowledge provides a conceptual content of the culture. Cognitive or existential assumptions 
provide a culture an essential cognitive patterns - epistemological, hermeneutical, and logical - through which people explain reality. In fact, people explain reality on the basis of what they perceive. Perception itself is the process of selection, organization, and interpretation (Jandt, 2004). So there is a high possibility to perceive same things differently by different people. Fiske (1990) mentions, giving Peirce's argument, that signs do not point the objective realities. They evoke subjective images in the mind. Word and contents of the word both are arbitrary which may lead to a reality.

For example, for Indians, a rainbow has two colors eras (hot) and patas (cold), but, for Americans, it has six colors. Likewise, western people believe in atoms, electrons, and gravity whereas eastern people believe in rakshasas, pretas, and other spirits. In short, it tells us what exists and what does not. It arranges our experience into categories, and organizes these categories into a larger system of knowledge.

Cultural knowledge includes assumptions and beliefs through which we make reality, perceive the nature of the world, and tell how it works. Cognitive assumptions also provide people a concept of time, self, and space. Uniform linear time is compatible with the mechanistic worldview which provides the notion of progress, evolution, and the future. This view emerged in the middle ages with the invention of the clock (Hiebert 2008) which emphasizes that time starts from the beginning and goes to an end so that it can also be divided into uniform intervals, for example second, minute, hour, day, month, year, and so on. Some cultures see time as a cyclical that never ends, always repeating birth, death, and rebirth. Others see time as a pendulum which goes forward and backward continuously. Similarly, the assumption of "self" provides people to pose themselves within the culture. For example, south Indian tribes have not got their individual self identity. So, an individual is recognized as the tribal group where one relates. In western culture, it may seem ridiculous where self is in the core of individual identity. Likewise, cognitive assumptions provide people with the concept of space, which is sacred and impure, and good fortune and misfortune. In fact, our culture teaches us how to construct and drive the way of life.

Similarly, for westerners, world is made by atoms and gravity. For most of the Asians and Africans, it might relate to spiritual beings. In Hinduism, 
life is a result of yesterday's deeds. In Buddhism culture is influenced by Theravada, life is equated with pain and suffering. By contrast, most of the western people believe that happiness can be achieved by hard-work and planning.

\section{The Affective Dimension}

Affective assumptions are about feelings, emotions and sensations. These assumptions emphasize attitudes, notions of beauty, like, dislike, joy, sorrow, pain, taste, smell, and so on. The affective dimension of culture is seen in standards of beauty, taste of cloths, food, furniture, house and other cultural products. People in one culture like spicy food, in another sweet or mild. Members of some communities learn to express their emotions which might be aggressive and argumentative while in others they learn to be self-controlled and tolerant. Emotions play a vital role in human relationship, and in our opinion of custom and friendship. Human communicates love, hate, scorn, happiness, and lots of other attitudes through facial expressions, tones of voices, and gestures. Our art, literature, music, dance, and drama are not only created for utilitarian purposes but our own enjoyment and emotional release. Some religions encourage the use of meditation, mysticism, and drugs to get inner peace, others stress happiness or ecstasy through frantic songs, dances and self torture. A Hindu priest prays to God to get free from cyclical rotation of birth, death, and rebirth whereas Christian minister prays God to be eternal. Life is considered as sorrow in Hinduism whereas it is taken as happiness in Christianity. Similarly, no two of us have same kind of sensation of taste, look, and smell (Jandt 2004) because our perception is different according to our culture where we are grown up.

Moreover, affective assumptions are the mental and psychological state associated with feelings, thoughts, and behaviors. For example, most of Chinese may water mouth by seeing a hanging dog in front of restaurant, whereas Norwegians may feel pain seeing the same scene. It happens because our psychological stimulations are different. Norwegians take a dog as a pet. So, they cannot imagine a dog as food whereas for Chinese it is meant for meat. Further, for Africans, saying "dog" to someone is taken as an insult.

\section{The Evaluative Dimension}

Evaluative dimension judges human relationships to be moral or immoral. 
Its assumptions provide people a guideline to judge, and to determine the truth and error; like and dislike; right and wrong; moral and immoral; cultured and uncultured; gentle and rough; fair and ugly; wise and foolish; and so on. It ranks some jobs high and others low, some way of eating is cultured other uncultured. Each culture has its one value which can be divided into three types. First, each culture evaluates cognitive beliefs to determine whether they are right or wrong. Second, culture judges the emotional expression of human life. It teaches us what beauty is and what ugliness is, what to love and what to hate. In some cultures people are encouraged to laugh freely, in others to laugh in mellow tone or just smile. Even within the same culture likes and dislikes vary greatly on the basis of settings and subcultures. Third, each culture judges, values and determines right and wrong. For example, Americans assume that honesty means telling facts even if that hurts people's feelings whereas in some of the Muslim cultures it is better to tell a lie than hurt people's feelings. Each culture has its own ethical code and culturally defined sins. It defines some acts to be righteous and others to be unethical or immoral. For example, in traditional Indian society it is sin for a woman to eat meal before her husband. In China a person must worship his or her ancestors by feeding them regularly, not to do so is sin.

Evaluative assumptions also determine the priorities of a culture (Hiebert 1984) by which one shapes the desires, likes, and dislikes. For example, Americans value the usage of high technological products, whereas Indian countryside people value religious purity. So that they separate space which is suppose to be pure in the house for religious purpose. They put images of God and worship daily. They respect and honor the priestly caste. The moral values differ from culture to culture. For example, eating during a lecture is taken immoral in most of the eastern schools and colleges. Students can be punished and restricted, whereas eating during the lectures is very common in western schools.

Social reality is not an absolute fact, as natural science has to be. It is socially constructed in the process of interaction with others. Socially constructed knowledge appears in the form of beliefs, shared values and social norms which is called culture. Social reality is not only the subjectively meaningful conduct of people's lives, "it is a world that originates in their thoughts and actions, and is maintained as real by these" (Berger and Luckmann 1966:33). 
Similarly, social reality must be understood both subjectively and objectively. For that, one should view society in terms of "ongoing dialectical process composed of the three moments of externalization, objectification, and internalization" (ibid. 129). From these three phases, people interact with a social world. Scott (2001) describes, Externalization is the production in social interaction, which consists of symbolic structures and its meaning comes to be shared by the people. Objectification is the process by which this production is collectively recognized, accepted and used. This is validated as being reliable and valuable. Internalization is a process by which the objectivity of the world is perceived as the facts in the course of socialization. Social reality is constructed through these three institutionalization phases. In another way, an institution is formed through the reciprocal habitualized activities. As a member of a group, a person supposes to perform actions and follows the rules. Over time, by following the rules or by performing shared habitual actions, an institution is created. This subjective rules form the objective institution.

In the similar way, Gergen (1985) argues that social reality is not automatically driven by the forces of nature. It is constructed in a process of understanding, which is the result of an active, cooperative, enterprise of persons in a relationship and it is construed through the historical and cultural bases. In the process of construction, there would be interaction between and/among two or more persons, there would be an object or event that we engage with, there would be persons or ideas that inform us, there would be power over and power resistance. Therefore, the construction of social reality always requires relations, assumptions about reality, and a voice or an action and reaction or response on one's voice or action. One should attempt to organize others' realities with his own realities. Interactions in everyday life institutionalize in a way that is the absolute truth.

Rapidly speeding up media technology, by continuous flows of media products, is compelling to create new social reality both, subjectively and objectively. Berger and Luckmann's analysis of society as a subjective reality describes how our conception of reality originates from our interaction with social structures. Those concepts or inventions become a part of our reality through the process of objectification of the inventions. When these objective realities are institutionalized, they appear as a form 
of culture (Berger and Luckmann, 1966).

Therefore, us and them or other is determined through the level of common values. People categorize us and them on the basis of their worldview. Similar worldview indicates nearer to (the) us. Berger and Luckmann (1966) state that commonalities bring closer and the closeness increases the level of interaction which enforces them to institutionalize the common values, an objective reality of the society. These commonalities make them to interact with the nearer groups, means with $u$ s than the others.

The following explanation on 'level of culture' helps us to understand culture in deeper way which helps to find out the reasons and issues of encounters among different cultures.

\section{Level of culture}

A culture has different levels from surface to core (Figure 3). We need to drill the cultural pattern to understand its level. On the surface level, visible elements such as cultural products, pattern of behavior, signs, rituals, and so on exist. Below the surface level beliefs, such as myths, rituals, dramas, and songs exist which give the conscious feelings, beliefs, and values of a culture. These are embedded to the social norms and values. Similarly, below this the unseen structures such as worldview themes, categories, logics, and epistemology exist (Hiebert, 1985). The surface level is

\section{Levels of Culture}

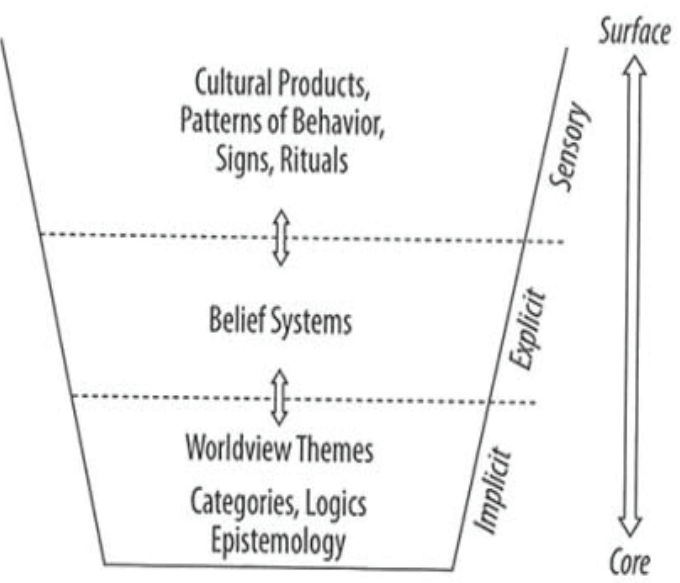

Figure 3: Level of Culture (Hiebert 2008, 33) 
sensory therefore we can see and feel it but bottom level is implicit which we cannot see, feel and identify. In addition, the surface understanding of a culture cannot give the root causes of encounters. Therefore we need to understand the explicit belief systems which lie in the middle of a culture and the implicit belief systems i.e. worldview themes, logics, and epistemology which lie in the core of a culture.

The following description on worldview functions helps us to understand what could be the reasons of encounters among the cultures.

\section{Functions of Worldview}

One's worldview does a number of essential functions. Our worldview provides us with cognitive foundations on which our systems are made, supplies rational justification of the systems. Our worldview validates and shapes our deepest cultural perceptions which we use to evaluate our experiences and select the best way of action (Hiebert 1985). It answers our fundamental epistemological questions. For example, where are we from? Where are we going to? What is wrong? How is it judged, and what is its remedy? What is sin? What is righteousness? What is universe? Where we are in universe? And so on. It provides us with the mental blueprints that guide our behavior. It emerges out of our interaction with the world. Worldviews are maps for living. For example, for the Muslim universe is a creation of Allah, we are servants of God and we are here to fulfill his wills which are reveled in the Quran. It guides our behavior with a map of reality. Hence, it does both predictive and prescriptive functions.

Our worldviews protects us from dangers by giving emotional strength. We face many uncontrollable forces and crises of drought, illness and death, and plagued by anxieties about an uncertain future, people get relief by their deepest cultural beliefs for comfort and security. We face the fear of death which is the most powerful emotion. We can face death itself as martyrs if we believe and have deep conviction on its purpose. Our worldview supports our fundamental beliefs with emotional reinforcements so that they cannot be easily destroyed.

Worldviews help us to integrate our culture. It organizes our ideas, feelings, and values into a more or less unified view of reality. Our worldview gives us a sense that we live in one world. Similarly, our worldview integrates and organizes ideas, beliefs, norms, and values. Simultaneously, it monitors cultural change (Kraft 1975). We confront with various kinds 
of new ideas, behaviors, knowledge, and new products in modern society. Our worldview helps us to adopt those which are similar to us and reject those which are not. When our worldview no longer meets our basic needs, desires, and demands we adopt new one. Worldviews provide psychological reassurance that the world is truly as we see it and a sense of peace in which we live in. People experience a worldview crisis when there is a gap between their worldview and their experience of reality.

When different dominant worldviews meet, encounters exist. Therefore, we need to analyze the situation from both synchronic and diachronic ways which help us to understand how people view the structure of the world and the myth of the people.

\section{Synchronic Analysis}

We can take an issue of Obama's bow on his visit to Japan and Saudi Arabia for an example to do synchronic analysis of the issue. His bow drew enough concerns and debates in the media. Most of the media cover the news of Obama's bow to the emperor of Japan and king of Saudi Arabia rather than his purpose of high level diplomatic visits. Many members of conservative party did criticize it in various ways. Why did this happen? Let's analyze the case from the Hiebert worldview model.

Political institutions such as state and local governments, commune, election bodies, political parties, democracy, are always strong and dominant in American culture. If we see from the cognitive dimension, they always rank these factors in the highest position. To be a president is the greatest achievement of life in the USA. It is the highest honorable and respectable post which is also the most powerful. They suppose the president can lead the world so he is taken as the king of the world. On the other hand, the highest and greatest figure of the world is not supposed to bow to anyone. That is why conservatives criticized his bow. But as Japanese social institutions are highly influenced by cultural themes, it is a pride to respect the emperor. Culturally he is highly honorable and respectable. Thus, bowing for Americans is a matter of suppression whereas it is a pride for Japanese. Therefore, Japanese children are taught bowing from the very beginning of their age to respect the other whereas American children are taught to be honored by the others. 


\section{Diachronic Analysis}

For diachronic analysis, we need to investigate how do cultural patterns develop from the historical past and what are bases of those patterns. In the peasant society, cognitive and evaluative themes were seen in a dominant role than the affective theme. People believed in the force of other world, the force of god and demons. For example, in the Indian belief system Brahma, Vishnu, Maheshora (gods) rakshas (devils) are the forces of other world. Likewise, in the Islamic belief system Allah, Archangels and devils were related to the forces of other world. In Chinese belief system, Jade emperor, Gods, goddesses were related to the forces of other world. In the hierarchy of the social system, religion was placed at the top. Naturally, religion was considered with ultimate cosmic realities: heavenly gods, demons, fate, karma, heaven, and hell (Hiebert 2008). Hard labor, sense of community, and mutual responsibility were the identities of the life where entertainment and excitement were far from the truth.

Though modernity is very complex and varies greatly from one culture to another, public concerned subjects were highly connected to the cognitive dimensions whereas affective and moral dimensions were related to the private sphere. As modernity always existed in the duality of naturalism and supernaturalism; this world and the other world; human centered and God centered; science and religion; materialistic secularism and heavenly spiritualism; and the public sphere and the private sphere, different cultures remained always in conflict. The encounters were found highly in the cognitive spheres. So, the 1st World War, the 2nd World War and holocaust happened. From the development of science, supernatural/natural dualism shifted from theocentric to human centric world. There was no belief or less belief in heaven, hell, or other worlds. Autonomous and free human beings became the centre of the universe. The world became observable. Religious beliefs, practices and religious institutions which once were in the centre of life became neglected. Sacred time and space gave away to secular time and space. Therefore, religion and embedded cultures were always in marginalized. But after the enlightenment, religions were taken as the subjective, emotional, and matter of personal faith (Hiebert 2008).

In the post modernity, which came to use in 1940s, cognitive and affective themes have appeared to be more dominant than moral theme. Postmodernity has shifted from the central focus of human centeredness 
to egocentrism where self is the centre of reality, self determination is in the highest value, self freedom is in the universal right, and self fulfillment is the optimum goal. The notion of deconstruction is found in the every structured values and norms; truth and knowledge; and belief and faith as it is supposed that those were created by modern western world to justify colonialism. In the affective themes we can get the concept of "I feel therefore I exist" (Hiebert 2008: 229). The development of technology, mass media, and popular cultures are helping to feel the importance and supremacy of the self. As this is the age of self actualization, there is room for self realization of spiritual realities including god and goddess. Post modernity critiques the unethical nature of modernity and the sciences.

In the post-postmodernism or the global society, cognitive themes have emerged in the areas of nature and direction of post modernity. They focus greatly on the enforcing phenomenon of the globalization. Economic neoliberalism or the expansionist capitalism, emergence of global governing bodies, the academy, rapid movement of the people, and the popular culture are the contributing factors to spread the globalism. Relatively isolated societies, for example Amazon, New Guinea, and India maintaining kinship in the primary form of social organization are being localized. In the global society, religion is revived as a key element in the identities of the people. Hybrid forms of entertainment, for example rap, rock, and pop music have been raised in the forms of music, art, and drama. The fundamental moral questions of isolation, poverty, operation, and violation all around the world remain unanswered. So in the globalism moral themes are taken more seriously than the other themes.

\section{Conclusion}

Worldview is a set of our presuppositions which lie in the core of a culture. We view the world and judge it according to our worldviews. Worldviews provide us cognitive foundation, validates our norms, and gives emotional security. We can do in-depth analysis by using Paul G. Hiebert's worldview model. The model has three dimensions: cognitive, affirmative and evaluative. Cognitive dimension relates to the knowledge which guides us to perceive the reality of self and surroundings. Affirmative dimension relates to our feelings, emotions, and behavior. So we react to the action on the basis of our feelings. Likewise, evaluative dimensions relate to the judgment - what is right and wrong. Different cultures have different 
cognitive, affirmative, and evaluative patterns. When different cultures come together, and interact each other many encounters happen in defining social reality, behavior pattern and judgment system. To understand cultural encounters we first need to understand cultural differences deeply through the drilling, synchronic, and diachronic methods.

\section{References}

Berger, Peter L. and Luckmann, Thomas (1966). The Social Construction of Reality: A Treatise in the Sociology of Knowledge. Garden City, NY: Anchor Books.

Fiske, John (1990). Introduction to Communication Studies (Second Edition). London and New York: Routledge.

Gergen, Kenneth J. (1985). 'The Social Constructionist Movement in Modern Psychology'. The American Psychological Association 40(3):266-275.

Hiebert, Paul G. (2008). Transforming Worldviews An Anthropological Understanding of how People Change. Michigan: Barker Academic, a division of Barker Publishing Group.

Hiebert, Paul G. (1985). Anthropological Insights for Missionaries. Michigan: Baker Book House.

Jandt, Fred E. (2004). An Introduction to Intercultural Communication Identities in a Global Community (Fourth edition). London: Sage Publications.

Kraft, Charles H. (1979). Christianity in Culture: a study in Dynamic biblical Theologizing in Cross-Cultural Perspectives. Maryknoll New York: Orbis Books.

Scott, W. Richard (2001). Institutions and Organizations: Foundations for Organizational Science (2nd Ed.). Thousand Oaks, Ca: Sage Publication. 